\title{
Effect of Body Mass Index and Hypertension on the Prognosis of Upper Tract Urothelial Carcinoma After Radical Nephroureterectomy
}

\author{
Minseung Lee ${ }^{1}$, Sang Hun Song ${ }^{1}$, Hakju Kim ${ }^{1}$, Sangchul Lee ${ }^{1}$, \\ Sung Kyu Hong ${ }^{1,2}$, Seok-Soo Byun ${ }^{1,2}$, Sang Eun Lee ${ }^{1}$, Jong Jin Oh ${ }^{1,2}$ \\ ${ }^{1}$ Department of Urology, Seoul National University Bundang Hospital, Seongnam, Korea \\ ${ }^{2}$ Department of Urology, Seoul National University College of Medicine, Seoul, Korea
}

\begin{abstract}
Purpose: To investigate the impact of preoperative underlying hypertension (HTN) and body mass index (BMI) on oncologic outcomes in patients with upper tract urothelial carcinoma (UTUC) who underwent radical nephroureterectomy (RNUx).

Materials and Methods: From May 2003 to December 2018, 453 UTUC patients who underwent RNUx at a single institution were enrolled in the study. All patients were divided into 2 groups according to preoperative HTN and BMI (cutoff $24 \mathrm{~kg} / \mathrm{m}^{2}$ ) and perioperative parameters and recurrence outcomes were compared. Multivariate Cox proportional hazard analysis was performed to identify the significance of HTN and BMI regarding UTUC recurrence.

Results: Among a total 453 UTUC patients, $233(51.4 \%)$ had HTN, and $222(49.0 \%)$ had BMI $\geq 24 \mathrm{~kg} / \mathrm{m}^{2}$. The HTN versus no-HTN group had similar perioperative outcomes, except for the rate of diabetes $(p<0.001)$. The high-BMI versus low-BMI group had similar outcomes, except for the prevalence of HTN $(p=0.026)$. During median follow-up of 23 months, 5-year recurrence-free survival rates were $76.2 \%$ in the HTN group and $79.9 \%$ in the non-HTN group ( $p=0.002$ ), and $77.3 \%$ in the low-BMl group and $79.0 \%$ in the high-BMl group $(p=0.007)$. Multivariate analysis showed that BMI (hazard ratio [HR], 0.740; $p=0.046)$, and HTN $(H R, 1.687 ; p=0.005)$ were significant predictors of cancer recurrence.

Conclusions: Among UTUC patients who underwent RNUx, patients with HTN and low-BMl showed worse prognosis regarding cancer recurrence. To validate our results, the mechanisms of association between HTN, BMI, and UTUC should be investigated in further prospective studies. (Korean J Urol Oncol 2020;18:201-208)
\end{abstract}

Key Words: Upper tract urothelial carcinoma $\cdot$ Body mass index $\cdot$ Hypertension $\cdot$ Survival

Received July 24, 2020, Revised September 20, 2020,

Accepted September 25, 2020

Corresponding Author: Jong Jin Oh

Department of Urology, Seoul National University Bundang Hospital, Seoul National University College of Medicine, 82 Gumi-ro 173beon-gil, Bundang-gu, Seongnam 13620, Korea

E-mail: bebsuzzang@naver.com

Tel: +82-31-787-7351, Fax: +82-31-787-4057

ORCID: https://orcid.org/0000-0003-0448-5992

\section{INTRODUCTION}

In a recent survey, the prevalence of urinary tract urothelial carcinoma (UTUC) was 1-2 per 100,000 in the United States, and 4.8 per 100,000 in the Republic of Korea. ${ }^{1,2}$ UTUC is a highly aggressive malignancy, and radical nephroureterectomy (RNUx) is the current standard treatment for patients with the disease. ${ }^{3}$ The 5-year recurrence-free survival (RFS) estimate was $70 \%$ in patients with UTUC treated with radical RNUx. ${ }^{4}$

This is an Open Access article distributed under the terms of the Creative Commons Attribution Non-Commercial License (http://creativecommons.org/licenses/by-nc/4.0/) which permits unrestricted non-commercial use, distribution, and reproduction in any medium, provided the original work is properly cited.

2020 (C) Copyright The Korean Urological Oncology Society and The Korean Prostate Society. All Rights Reserved. 
Tumor stage, lymph node metastasis, chronic urinary tract infection, hydronephrosis, and smoking are closely related to recurrence of UTUC. ${ }^{5-9}$ Hypertension (HTN) and obesity, which are metabolic factors, have been studied regarding cancer. Many studies have reported regarding a relationship between HTN and body mass index (BMI) and renal cell carcinoma, bladder cancer, prostate cancer, breast cancer, and lung cancer. ${ }^{10-17}$ However, there are few studies about the relationship between HTN, BMI, and UTUC in patients with RNUx. One study reported that patients with low-BMI $\left(<18.5 \mathrm{~kg} / \mathrm{m}^{2}\right)$ had a worse prognosis, regarding RFS and cancer-specific survival (CSS), than patients with normal BMI $\left(18.5-25 \mathrm{~kg} / \mathrm{m}^{2}\right)$ or obesity (BMI $\left.\geq 25 \mathrm{~kg} / \mathrm{m}^{2}\right)$. ${ }^{18}$ Another study reported that diabetes mellitus was related to postoperative bladder cancer recurrence in China. ${ }^{19}$ Therefore, we investigated the influence of HTN and BMI on oncologic outcomes in patients with UTUC treated with RNUx.

\section{MATERIALS AND METHODS}

\section{Study Population}

From May 2003 to December 2018, after obtaining institutional review board approval (B-1907-552-110), UTUC patients who underwent RNUx at one institution were enrolled in the study. We excluded patients with metastasis at the time of RNUx, and patients with incomplete data. Thus, 453 UTUC patients were enrolled.

\section{Data Collection and Pathologic Evaluation}

Baseline data before RNUx were collected, including preoperative glomerular filtration rate, tumor location and laterality, and the presence of hydronephrosis, HTN, or concurrent bladder tumor at RNUx. The patient who has HTN defined to who were taking HTN medication regardless of the type of medication before surgery. All surgical specimens after RNUx were processed according to standard pathologic procedures. Tumors were staged according to the 2009 American Joint Committee on Cancer and International Union for Cancer Control tumor-node-metastasis cancer staging system. ${ }^{20}$ All patients had pathologically confirmed transitional cell carcinoma in the upper urinary tract after RNUx.

RNUx was performed using an open, laparoscopic, or ro- botic method. Open RNUx was carried out in 164 patients (36.2\%), laparoscopic RNUx in 143 (31.6\%), and robotic-assisted RNUx in 146 (32.2\%). Most open surgery was done by flank incision for nephrectomy, followed by a Gibson incision for distal ureteral resection. Lymph node dissection was performed when enlarged lymph nodes were found on preoperative computed tomography (CT) scans or were palpable during surgery. No patients had known metastatic disease at the time of surgery, as shown by radiography and CT scan.

Patients were generally followed-up every 3 months during the first 2 years after surgery, every 6 months from $2-5$ years after surgery, and annually thereafter. Follow-up examinations consisted of history taking, physical examination, routine blood evaluation, urinary cytology, cystoscopic evaluation of the bladder, and radiographic evaluation of the chest and abdomen.

\section{Statistical Analyses}

Statistical analyses were carried out using IBM SPSS Statistics ver. 22.0 (IBM Co., Armonk, NY, USA). Differences in continuous variables were analyzed by paired t-test. The chi-square test was carried out to assess differences in covariate distribution among the 2 categories. The primary endpoints were RFS, which was defined as the interval between surgery and the subsequent appearance of either local failure (in regional lymph nodes) at the operative site or in the bladder, and distant metastasis. Survival analysis was carried out using the Kaplan-Meier method. Multivariate survival analyses were carried out using the Cox regression model.

\section{RESULTS}

Among a total of 453 patients, 233 (51.4\%) had a history of HTN (Table 1). There were no significant differences between the HTN and no-HTN groups, except for the rate of diabetes mellitus $(27.5 \%$ vs. $10.0 \%, \mathrm{p}<0.001)$.

Median BMI was $24.06 \mathrm{~kg} / \mathrm{m}^{2}$ (interquartile range, 21.78$\left.26.08 \mathrm{~kg} / \mathrm{m}^{2}\right)$ in the 453 patients, among whom $222(49.0 \%)$ had high-BMI $\left(\geq 24 \mathrm{~kg} / \mathrm{m}^{2}\right)$. High-BMI patients had a higher rate of HTN than the low-BMI group (56.8\% vs. $46.3 \%$, $\mathrm{p}=0.026)$ and a lower rate of transfusions $(14.0 \% \mathrm{vs}, 24.7 \%$, $\mathrm{p}=0.046$ ). Other perioperative parameters, including surgical 
Table 1. Baseline and perioperative results among 453 patients who underwent radical nephroureterctomy for upper tract urothelial carcinoma

\begin{tabular}{|c|c|c|c|c|c|c|}
\hline Variable & $\begin{array}{l}\operatorname{HTN}(-) \\
(\mathrm{N}=220)\end{array}$ & $\begin{array}{l}\mathrm{HTN}(+) \\
(\mathrm{N}=233)\end{array}$ & p-value & $\begin{array}{c}\mathrm{BMI}<24 \mathrm{~kg} / \mathrm{m}^{2} \\
\quad(\mathrm{~N}=231)\end{array}$ & $\begin{array}{c}\mathrm{BMI} \geq 24 \mathrm{~kg} / \mathrm{m}^{2} \\
(\mathrm{~N}=222)\end{array}$ & p-value \\
\hline Age (yr) & $65.28(59-73)$ & $70.42(64-77)$ & 0.152 & $68.79(63-77)$ & $67.03(61-74)$ & 0.345 \\
\hline Sex & & & 0.174 & & & 0.138 \\
\hline Male & $162(73.6)$ & $158(67.8)$ & & $156(67.5)$ & $164(73.9)$ & \\
\hline Female & $58(26.4)$ & $75(32.2)$ & & $75(32.5)$ & $58(26.1)$ & \\
\hline Smoking & & & 0.240 & & & 0.757 \\
\hline Yes & $38(17.3)$ & $31(13.3)$ & & $34(14.7)$ & $35(15.8)$ & \\
\hline No & $182(82.7)$ & $202(86.7)$ & & $197(85.3)$ & $187(84.2)$ & \\
\hline ECOG & & & 0.479 & & & 0.552 \\
\hline 0 & $8(3.6)$ & $14(6.0)$ & & $9(3.9)$ & $13(5.9)$ & \\
\hline 1 & $208(94.5)$ & $214(91.8)$ & & $217(93.9)$ & $205(92.3)$ & \\
\hline $3-5$ & $4(1.8)$ & $5(2.2)$ & & $5(2.2)$ & $4(1.8)$ & \\
\hline Preoperative GFR & $73.7(59.1-86.8)$ & $63.1(49.4-74.0)$ & 0.495 & $68.1(51-82)$ & $68.3(54-80)$ & 0.776 \\
\hline Laterality & & & 0.054 & & & 0.261 \\
\hline Left & $109(49.5)$ & $138(58.4)$ & & $129(55.8)$ & $116(52.3)$ & \\
\hline Right & $111(50.5)$ & $95(40.8)$ & & $100(43.3)$ & $106(47.7)$ & \\
\hline Bilateral & $0(0)$ & $2(0.9)$ & & $2(0.9)$ & $0(0)$ & \\
\hline Location & & & 0.764 & & & 0.268 \\
\hline Lower ureter & $44(22.0)$ & $44(18.9)$ & & 41 (17.7) & $47(21.2)$ & \\
\hline Mid ureter & $18(8.2)$ & $34(14.6)$ & & $21(9.1)$ & $31(14.0)$ & \\
\hline Upper ureter & $26(11.8)$ & $35(15.0)$ & & $33(14.3)$ & $28(12.6)$ & \\
\hline Pelvis & $94(42.7)$ & $67(28.8)$ & & $83(35.9)$ & $78(35.1)$ & \\
\hline Multiple & $38(17.3)$ & $53(22.7)$ & & $53(22.9)$ & $38(17.1)$ & \\
\hline Hydronephrosis & & & 0.054 & & & 0.546 \\
\hline Yes & $138(62.7)$ & $166(71.2)$ & & $152(65.8)$ & $152(68.5)$ & \\
\hline No & $82(37.3)$ & $67(28.8)$ & & $79(34.2)$ & $70(31.5)$ & \\
\hline Diabetes mellitus & & & $<0.001$ & & & 0.161 \\
\hline Yes & $22(10.0)$ & $64(27.5)$ & & $38(16.5)$ & 48 (21.6) & \\
\hline No & $198(90.0)$ & $169(72.5)$ & & $193(83.5)$ & $174(78.4)$ & \\
\hline HTN & & & & & & 0.026 \\
\hline Yes & & & & $107(46.3)$ & $126(56.8)$ & \\
\hline No & & & & $124(53.7)$ & $96(43.2)$ & \\
\hline Operation method & & & 0.707 & & & 0.288 \\
\hline Open & $78(35.5)$ & $86(36.9)$ & & $91(39.4)$ & $73(32.9)$ & \\
\hline Laparoscopic & $67(30.5)$ & $76(32.6)$ & & $72(31.2)$ & $71(32.0)$ & \\
\hline Robotic & $75(34.1)$ & $71(30.5)$ & & $68(29.4)$ & $78(35.1)$ & \\
\hline Mean operation time & $225(185-270)$ & $226.45(175-267.5)$ & 0.651 & $224.1(175-265)$ & $232.0(180-275)$ & 0.520 \\
\hline Estimated blood loss & $267(100-300)$ & $261.93(100-300)$ & 0.249 & $277.0(100-300)$ & $251.7(100-300)$ & 0.067 \\
\hline Transfusion rate $(\%)$ & 20.5 & 18.5 & 0.591 & 24.7 & 14.0 & 0.046 \\
\hline Complications & $7(3.2)$ & $9(3.9)$ & 0.695 & $7(3.0)$ & $9 \quad(4.1)$ & 0.555 \\
\hline
\end{tabular}

Values are presented as median (interquartile range) or number (\%) unless otherwise indicated.

HTN: hypertension, BMI: body mass index, ECOG: Eastern Copperative Oncology group, GFR: glomerular filtration rate.

methods, operation time, were similar between the 2 groups.

Clinical and pathologic profiles for the 453 patients were stratified by HTN, and BMI (Table 1). In HTN versus no-HTN patients, significant differences were evident in tumor location $(p=0.012)$, tumor laterality $(p=0.054)$, and the presence of preoperative diabetes mellitus $(\mathrm{p}<0.001)$, and hydronephrosis $(\mathrm{p}=0.054)$. In low-BMI versus high-BMI patients, a significant difference was evident in the presence of preoperative HTN ( $\mathrm{p}=0.026$ ).

Table 2 shows pathologic outcomes according to each group. Overall, 168 patients had pathologic pT3-4 (37.1\%). Pathologic stage, grade, and lymph node invasion were sim- 
Table 2. Pathologic and survival outcomesin patient who underwent radical nephroureterctomy for upper tract urothelial carcinoma

\begin{tabular}{|c|c|c|c|c|c|c|}
\hline Variable & $\begin{array}{l}\mathrm{HTN}(-) \\
(\mathrm{N}=220)\end{array}$ & $\begin{array}{l}\mathrm{HTN}(+) \\
(\mathrm{N}=233)\end{array}$ & p-value & $\begin{array}{c}\mathrm{BMI}<24 \mathrm{~kg} / \mathrm{m}^{2} \\
\quad(\mathrm{~N}=231)\end{array}$ & $\begin{array}{c}\mathrm{BMI} \geq 24 \mathrm{~kg} / \mathrm{m}^{2} \\
(\mathrm{~N}=222)\end{array}$ & $\mathrm{p}$-value \\
\hline $\mathrm{T}$ stage & & & 0.162 & & & 0.053 \\
\hline $\mathrm{Ta}$ & $4(1.8)$ & $2(0.9)$ & & $3(1.3)$ & $3(1.4)$ & \\
\hline $\mathrm{T} 1$ & $64(29.1)$ & $63(27.0)$ & & $55(23.8)$ & $72(32.4)$ & \\
\hline $\mathrm{T} 2$ & $72(32.7)$ & $75(32.2)$ & & $70(30.3)$ & $77(34.7)$ & \\
\hline $\mathrm{T} 3$ & $63(28.6)$ & $82(35.2)$ & & $88(38.1)$ & $57(25.7)$ & \\
\hline $\mathrm{T} 4$ & $12(5.5)$ & $11(4.7)$ & & $11(4.8)$ & $12(5.4)$ & \\
\hline Tis & $5(2.3)$ & $0(0)$ & & $4(1.7)$ & $1(0.5)$ & \\
\hline Lymph node invasion & & & 0.466 & & & 0.525 \\
\hline $\mathrm{Nx}$ & $125(56.8)$ & $138(59.2)$ & & $137(59.3)$ & $126(56.8)$ & \\
\hline N0 & $41(18.7)$ & $55(23.6)$ & & $47(20.3)$ & $49(22.1)$ & \\
\hline$\geq \mathrm{N} 1$ & $21(9.5)$ & $24(10.3)$ & & $21(9.1)$ & $24(10.8)$ & \\
\hline Grade & & & 0.059 & & & 0.553 \\
\hline I & $2(0.9)$ & $0(0)$ & & $0(0)$ & $2(0.9)$ & \\
\hline II & $113(51.4)$ & $112(48.1)$ & & $115(50.2)$ & $110(49.5)$ & \\
\hline III & $101(45.9)$ & $121(51.9)$ & & $114(49.8)$ & $108(48.6)$ & \\
\hline Positive surgical margin (\%) & $15(6.8)$ & $15(6.4)$ & 0.871 & $21(9.1)$ & $9(4.1)$ & 0.031 \\
\hline Recurrence $(\%)$ & $122(55.5)$ & $152(65.2)$ & 0.033 & $149(64.5)$ & $125(56.3)$ & 0.074 \\
\hline \multicolumn{7}{|l|}{ Recurrence site } \\
\hline Bladder & 69 & 84 & & 79 & 74 & \\
\hline Lymph node & 52 & 67 & & 64 & 55 & \\
\hline Lung & 33 & 35 & & 37 & 31 & \\
\hline Bone & 16 & 28 & & 27 & 17 & \\
\hline Liver & 16 & 18 & & 18 & 16 & \\
\hline Local & 8 & 15 & & 11 & 12 & \\
\hline Others* & 34 & 48 & & 46 & 36 & \\
\hline Cancer specific survival (\%) & $207(94.1)$ & $214(91.8)$ & 0.802 & $212(91.8)$ & $209(94.1)$ & 0.300 \\
\hline Overall survival $(\%)$ & $199(90.5)$ & $208(89.3)$ & 0.661 & $200(86.6)$ & $207(93.2)$ & 0.143 \\
\hline Adjuvant chemotherapy (\%) & $66(30.0)$ & $69(29.6)$ & 0.880 & $67(29.0)$ & $68(30.6)$ & 0.683 \\
\hline
\end{tabular}

Values are presented number (\%).

HTN: hypertension, BMI: body mass index.

*Others: prostate, pelvic cavity, colorectal, adrenal, brain, etc.

ilar between the groups. The positive surgical margin was greater in the low-BMI than high-BMI group $(9.1 \%$ vs. $4.1 \%, \mathrm{p}=0.031$ ). During 42.0-month follow-up, cancer recurrence was observed in 274 patients $(60.5 \%)$. The most frequent sites of recurrence were the bladder (153 of 453 patients, $33.8 \%$ ), lymph nodes (119 of 453, 26.3\%), lung ( 68 of $453,15.0 \%$ ), and bone (44 of $453,9.7 \%$ ). Adjuvant chemotherapy rate was no significantly difference between HTN and no-HTN patients $(29.6 \%$ vs. $30.0 \%, \mathrm{p}=0.880)$, also no significantly difference between low-BMI and highBMI group ( $29.0 \%$ vs. $30.6 \%, \mathrm{p}=0.683)$. Cancer recurrence was more frequent in the HTN than no-HTN group $(65.2 \%$ vs. $55.5 \%, \mathrm{p}=0.033$ ). Five-year RFS rates were $76.2 \%$ in the HTN group and $79.9 \%$ in the no-HTN group (log-rank, $\mathrm{p}=0.002$ ) (Fig. 1), and those were $77.3 \%$ in the low-BMI group and $79.0 \%$ in the high-BMI group (log-rank, $\mathrm{p}=0.007$ ) (Fig. 2). Five-year intravesical RFS rates were no significant difference in the HTN group and in the no-HTN group $(66.4 \%$ vs. $65.7 \%$, log-rank $\mathrm{p}=0.120)$, also no difference in low-BMI group and in the high-BMI group $(67.4 \%$ vs. $64.7 \%$ log-rank $\mathrm{p}=0.438$ ).

Multivariate Cox proportional hazard analysis showed the significance of BMI and HTN in relation to cancer recurrence after adjusting for other factors (Table 3 ). That is, BMI (hazard ratio [HR], 0.740; 95\% confidence interval [CI], 0.551-0.995; p=0.046) and HTN (HR, 1.687; 95\% CI, 1.174-2.426; $\mathrm{p}=0.005$ ) were significant predictors of cancer recurrence. That is, BMI (hazard ratio [HR], 0.740; 95\% 


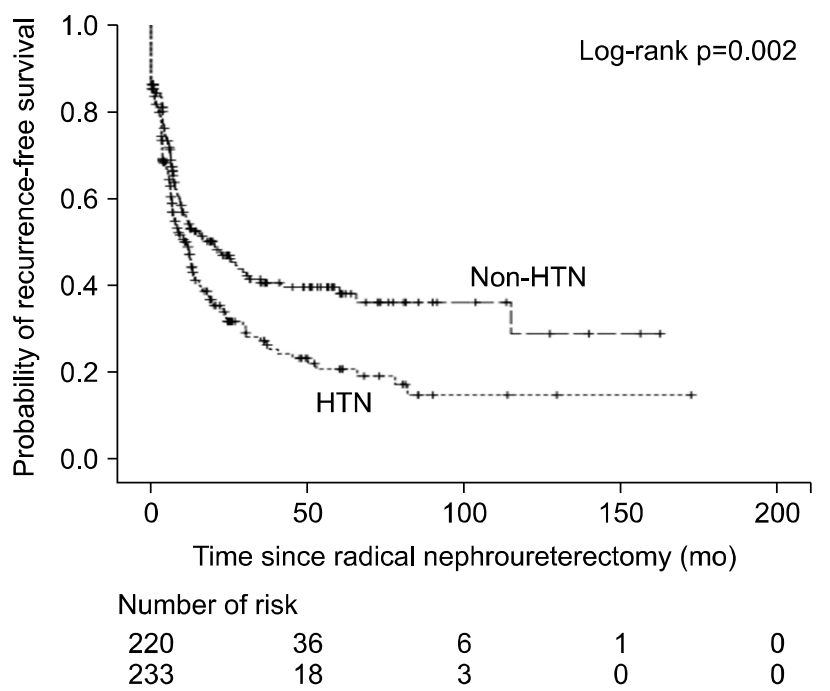

Fig. 1. Kaplan-Meier analysis of the association of hypertension (HTN) with recurrence-free survival in 453 patients with upper tract urothelial carcinoma treated with radical nephroureterectomy.

confidence interval [CI], 0.551-0.995; $\mathrm{p}=0.046)$ and HTN (HR, 1.687; 95\% CI, 1.174-2.426; $\mathrm{p}=0.005)$ were significant predictors of cancer recurrence.

Five-year OS rates were no significant difference in the HTN group and in the no-HTN group $(89.3 \%$ vs, $90.5 \%$, $\log$-rank $\mathrm{p}=0.661$ ), also no difference in low-BMI group and in the high-BMI group ( $86.6 \% \mathrm{vs,} 93.2 \% \log$-rank $\mathrm{p}=0.143)$. Five-year CSS rates were no significant difference in the HTN group and in the no-HTN group (91.8\% vs. $94.1 \%$, $\log$-rank $\mathrm{p}=0.802$ ), also no difference in low-BMI group and in the high-BMI group ( $91.8 \%$ vs. $94.1 \% \log$-rank $\mathrm{p}=0.300)$ (Table 2). Multivariate Cox proportional hazard analysis showed that BMI and HTN are not significantly related to OS and CSS after adjusting for other factors (Tables 4, 5).

\section{DISCUSSION}

Although UTUC is not a common cancer, it has a high recurrence rate. In particular, smoking status, tumor stage, and lymph node metastases are associated with UTUC recurrence. This study assessed how obesity and HTN, which continue to increase in incidence, might be linked to UTUC. Thus, in 453 RNUx-operated UTUC patients, we found that RFS in patients with high-BMI, without HTN, was good. Several papers exist about the relationship between renal cell carcinoma and HTN and BMI, but few

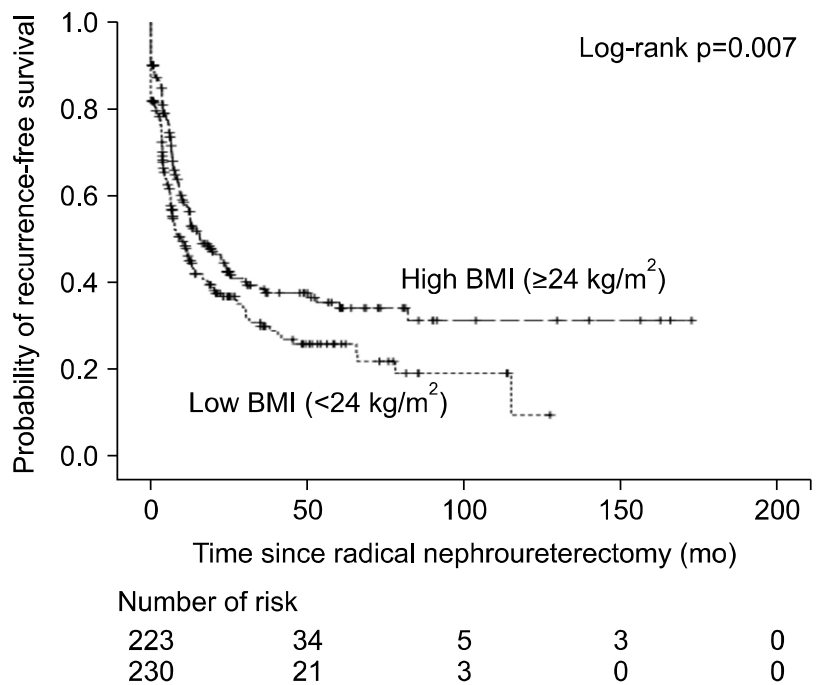

Fig. 2. Kaplan-Meier analysis of the association of body mass index (BMI) with recurrence-free survival in 453 patients with upper tract urothelial carcinoma treated radical nephroureterectomy.

studies have been published about the relationship between UTUC and HTN and BMI.

In one study, when 236 UTUC patients underwent RNUx in China, higher BMI was associated with better RFS and $\mathrm{CSS}^{18}$ In another paper, low-BMI was an independent predictor of worse CSS on multivariate analysis in 103 obese patients (HR, 2.210; $\mathrm{p}=0.047){ }^{21}$ In patients with high-BMI, increased fat between the kidney and Gerota's fascia may suggest that the higher the BMI, the better will be survival, as UTUC has difficulty in transitioning and invading beyond the fascia. ${ }^{18}$ Furthermore, Obesity is associated with hyperinsulinemia, which may increase the secretion of peptide hormones such as leptin and adiponectin. These peptide hormones promote the proliferation and activation of natural killer cells, resulting in antitumor effects. ${ }^{22}$

Recently, a large-scale prospective study of 226,505 patients with UTUC reported that HTN was related to UTUC by using univariate analysis. HTN are components of metabolic syndrome, which is involved in cancer development. HTN affects apoptosis, which regulates cell turnover in other solid cancers. HTN also has a metabolic pathway associated with oxidative stress, another cancer-causing factor. ${ }^{23}$

In this study, the patient with HTN and low-BMI showed higher recurrence rate than the patient with high-BMI and without HTN (67.6\% vs. $47.4 \% \mathrm{p}=0.013)$. Although, BMI and HTN is generally positively correlated, those factors 
Table 3. Univariate and multivariate Cox proportional hazard analysis predict significant factors to cancer progression after radical nephroureterctomy in upper tract urothelial carcinoma patients

\begin{tabular}{|c|c|c|c|c|c|c|}
\hline \multirow{2}{*}{ Variable } & \multicolumn{3}{|c|}{ Univariate analysis } & \multicolumn{3}{|c|}{ Multivariate analysis } \\
\hline & $\mathrm{HR}$ & $95 \% \mathrm{CI}$ & p-value & HR & $95 \% \mathrm{CI}$ & p-value \\
\hline Age & 1.011 & $0.999-1.023$ & 0.076 & - & - & - \\
\hline BMI $\left(<24\right.$ vs. $\left.\geq 24 \mathrm{~kg} / \mathrm{m}^{2}\right)$ & 0.724 & $0.569-0.921$ & 0.007 & 0.754 & $0.589-0.964$ & 0.024 \\
\hline History of smoking & 0.956 & $0.685-1.333$ & 0.789 & - & - & - \\
\hline Adjuvant Chemotherapy & 3.389 & $2.658-4.321$ & $<0.005$ & 2.986 & $2.250-3.962$ & $<0.005$ \\
\hline Tumor stage ( $\geq \mathrm{T} 3$ or not) & 2.142 & $1.683-2.726$ & $<0.005$ & 1.085 & $0.814-1.446$ & 0.579 \\
\hline Tumor grade ( $\geq 3$ or not) & 1.156 & $0.909-1.469$ & 0.236 & - & - & - \\
\hline Lymph node invasion & 1.377 & $1.083-1.751$ & 0.009 & 1.236 & $0.964-1.585$ & 0.095 \\
\hline Positive surgical margin & 2.789 & $1.890-4.114$ & $<0.005$ & 2.355 & $1.580-3.510$ & $<0.005$ \\
\hline Postoperative GFR & 0.997 & $0.991-1.003$ & 0.411 & - & - & - \\
\hline Presence of preoperative Hydronephrosis & 1.444 & $1.101-1.892$ & 0.008 & 1.174 & $0.889-1.551$ & 0.258 \\
\hline Presence of preoperative DM & 1.130 & $0.836^{-1.527}$ & 0.431 & - & - & - \\
\hline Presence of preoperative HTN & 1.446 & $1.135-1.842$ & 0.002 & 1.492 & $1.167-1.908$ & 0.001 \\
\hline
\end{tabular}

HR: hazard ratio, CI: confidence interval, BMI: body mass index, GFR: glomerular filtration rate, DM: diabetes mellitus, HTN: hypertension.

Table 4. Univariate and multivariate Cox proportional hazard analysis predict significant factors to overall survival on after radical nephroureterctomy in upper tract urothelial carcinoma patients

\begin{tabular}{|c|c|c|c|c|c|c|}
\hline \multirow{2}{*}{ Variable } & \multicolumn{3}{|c|}{ Univariate analysis } & \multicolumn{3}{|c|}{ Multivariate analysis } \\
\hline & HR & $95 \% \mathrm{CI}$ & p-value & HR & $95 \% \mathrm{CI}$ & p-value \\
\hline Age & 1.085 & $1.046-1.126$ & $<0.005$ & 1.108 & $1.061-1.156$ & $<0.005$ \\
\hline BMI $\left(<24\right.$ vs. $\left.\geq 24 \mathrm{~kg} / \mathrm{m}^{2}\right)$ & 0.467 & $0.251-0.868$ & 0.016 & 0.102 & $0.314-1.111$ & 0.102 \\
\hline History of smoking & 0.651 & $0.257-1.652$ & 0.367 & & & \\
\hline Adjuvant Chemotherapy & 3.737 & $2.056-6.792$ & $<0.005$ & 3.916 & $1.868-8.210$ & $<0.005$ \\
\hline Tumor stage ( $\geq \mathrm{T} 3$ or not) & 4.770 & $2.531-8.991$ & $<0.005$ & 2.148 & $1.025-4.498$ & 0.043 \\
\hline Tumor grade ( $\geq 3$ or not) & 1.230 & $0.680-2.226$ & 0.494 & - & - & - \\
\hline Lymph node invasion & 1.214 & $0.676-2.181$ & 0.515 & - & - & - \\
\hline Positive surgical margin & 2.730 & $1.067-6.892$ & 0.036 & 1.266 & $0.493-3.250$ & 0.623 \\
\hline Postoperative GFR & 1.008 & $0.993-1.023$ & 0.286 & - & - & - \\
\hline Presence of preoperative Hydronephrosis & 1.043 & $0.554-1.960$ & 0.897 & - & - & - \\
\hline Presence of preoperative DM & 1.664 & $0.656-4.223$ & 0.283 & - & - & - \\
\hline Presence of preoperative HTN & 1.309 & $0.728-2.354$ & 0.368 & - & - & - \\
\hline
\end{tabular}

HR: hazard ratio, CI: confidence interval, BMI: body mass index, GFR: glomerular filtration rate, DM: diabetes mellitus, HTN: hypertension.

can affect in a contradictory manner. A study showed that obese patients had lower mortality by cardiovascular and ischemic heart disease than non-obese patients in hypertensive patients. ${ }^{24}$ Like this research, BMI and HTN can act as independent variables and even obesity showed protective effects in some studies regarding UTUC patients. But it is difficult to clearly describe underlying pathophysiology of this contradictorily looking phenomenon. This is considered to be a limitation, and further investigation would be needed.
Our study has several limitations. First, as a retrospective study, each patient had a different follow-up period, and various biases were generated, such as inability to adjust the treatment method for UTUC. Second, BMI and HTN were assessed just before surgery, but all patients who underwent surgery were not being treated for HTN, so it was unclear how well HTN was being treated and controlled. Third, the effect of HTN and BMI on OS and CSS in UTUC patients was investigated, but there was no statistically significant difference in this study. Despite these limitations, our paper 
Table 5. Univariate and multivariate Cox proportional hazard analysis predict significant factors to cancer specific survival on after radical nephroureterctomy in upper tract urothelial carcinoma patients

\begin{tabular}{|c|c|c|c|c|c|c|}
\hline \multirow{2}{*}{ Variable } & \multicolumn{3}{|c|}{ Univariate analysis } & \multicolumn{3}{|c|}{ Multi-variate analysis } \\
\hline & HR & $95 \% \mathrm{CI}$ & p-value & $\mathrm{HR}$ & $95 \% \mathrm{CI}$ & p-value \\
\hline Age & 1.059 & $1.012-1.108$ & 0.013 & 1.092 & $1.032-1.155$ & 0.002 \\
\hline BMI $\left(<24\right.$ vs. $\left.\geq 24 \mathrm{~kg} / \mathrm{m}^{2}\right)$ & 0.797 & $0.368-1.724$ & 0.564 & - & - & - \\
\hline History of smoking & 0.664 & $0.199-2.211$ & 0.504 & - & - & - \\
\hline Adjuvant Chemotherapy & 10.480 & $3.948-27.819$ & $<0.005$ & 8.632 & $2.840-26.237$ & $<0.005$ \\
\hline Tumor stage ( $\geq \mathrm{T} 3$ or not) & 8.934 & $3.360-23.751$ & $<0.005$ & 2.850 & $0.978-8.302$ & 0.055 \\
\hline Tumor grade ( $\geq 3$ or not) & 1.066 & $0.493-2.308$ & 0.870 & - & - & - \\
\hline Lymph node invasion & 1.282 & $0.594-2.766$ & 0.527 & - & - & - \\
\hline Positive surgical margin & 5.013 & $1.869-13.445$ & 0.001 & 2.306 & $0.864-6.153$ & 0.095 \\
\hline Postoperative GFR & 1.006 & $0.987-1.026$ & 0.548 & - & - & - \\
\hline Presence of preoperative Hydronephrosis & 1.324 & $0.600-2.919$ & 0.487 & - & - & - \\
\hline Presence of preoperative DM & 1.637 & $0.491-5.454$ & 0.422 & - & - & - \\
\hline Presence of preoperative HTN & 1.844 & $0.835-4.069$ & 0.130 & - & - & - \\
\hline
\end{tabular}

HR: hazard ratio, CI: confidence interval, BMI: body mass index, GFR: glomerular filtration rate, DM: diabetes mellitus, HTN: hypertension.

suggests that HTN and BMI tend to relapse in UTUC. Therefore, further prospective studies are needed to investigate the relationship between HTN, BMI, and UTUC.

\section{CONCLUSIONS}

Among UTUC patients who underwent RNUx, HTN versus no-HTN was associated with worse RFS. Further, low-BMI $\left(<24 \mathrm{~kg} / \mathrm{m}^{2}\right)$ was associated with worse RFS than high-BMI. Future prospective studies are required to validate our results, and basic or translational research should be conducted to determine potential mechanisms for the relationships between HTN, BMI, and UTUC.

\section{CONFLICT OF INTEREST}

The authors claim no conflicts of interest.

\section{REFERENCES}

1. Koo KC, Lee KS, Chung BH. Urologic cancers in Korea. Jpn J Clin Oncol 2015;45:805-11.

2. Siegel RL, Miller KD, Jemal A. Cancer statistics, 2016. CA Cancer J Clin 2016;66:7-30.

3. Rouprêt M, Babjuk M, Compérat E, Zigeuner R, Sylvester RJ, Burger M, et al. European Association of Urology Guidelines on upper urinary tract urothelial carcinoma:
2017 update. Eur Urol 2018;73:111-22.

4. Remzi M, Haitel A, Margulis V, Karakiewicz P, Montorsi F, Kikuchi E, et al. Tumour architecture is an independent predictor of outcomes after nephroureterectomy: a multiinstitutional analysis of 1363 patients. BJU Int 2009;103: 307-11.

5. Rink M, Xylinas E, Margulis V, Cha EK, Ehdaie B, Raman JD, et al. Impact of smoking on oncologic outcomes of upper tract urothelial carcinoma after radical nephroureterectomy. Eur Urol 2013;63:1082-90.

6. Messer JC, Terrell JD, Herman MP, Ng CK, Scherr DS, Scoll B, et al. Multi-institutional validation of the ability of preoperative hydronephrosis to predict advanced pathologic tumor stage in upper-tract urothelial carcinoma. Urol Oncol 2013;31:904-8.

7. Chung PH, Krabbe LM, Darwish OM, Westerman ME, Bagrodia A, Gayed BA, et al. Degree of hydronephrosis predicts adverse pathological features and worse oncologic outcomes in patients with high-grade urothelial carcinoma of the upper urinary tract. Urol Oncol 2014;32:981-8.

8. Oosterlinck W, Solsona E, van der Meijden AP, Sylvester $\mathrm{R}$, Böhle A, Rintala E, et al. EAU guidelines on diagnosis and treatment of upper urinary tract transitional cell carcinoma. Eur Urol 2004;46:147-54.

9. Colin P, Koenig P, Ouzzane A, Berthon N, Villers A, Biserte J, et al. Environmental factors involved in carcinogenesis of urothelial cell carcinomas of the upper urinary tract. BJU Int 2009;104:1436-40.

10. Martin RM, Vatten L, Gunnell D, Romundstad P, Nilsen TI. Components of the metabolic syndrome and risk of prostate cancer: the HUNT 2 cohort, Norway. Cancer 
Causes Control 2009;20:1181-92.

11. Lindgren A, Pukkala E, Nissinen A, Tuomilehto J. Blood pressure, smoking, and the incidence of lung cancer in hypertensive men in North Karelia, Finland. Am J Epidemiol 2003;158:442-7.

12. Freedland SJ, Sun L, Kane CJ, Presti JC Jr, Terris MK, Amling CL, et al. Obesity and oncological outcome after radical prostatectomy: impact of prostate-specific antigenbased prostate cancer screening: results from the Shared Equal Access Regional Cancer Hospital and Duke Prostate Center databases. BJU Int 2008;102:969-74.

13. Kamat AM, Shock RP, Naya Y, Rosser CJ, Slaton JW, Pisters LL. Prognostic value of body mass index in patients undergoing nephrectomy for localized renal tumors. Urology 2004;63:46-50.

14. Schips L, Lipsky K, Zigeuner R, Gidaro S, Salfellner M, Rehak $\mathrm{P}$, et al. Does overweight impact on the prognosis of patients with renal cell carcinoma? A single center experience of 683 patients. J Surg Oncol 2004;88:57-61.

15. Lee CT, Dunn RL, Chen BT, Joshi DP, Sheffield J, Montie JE. Impact of body mass index on radical cystectomy. J Urol 2004;172(4 Pt 1):1281-5.

16. Hafron J, Mitra N, Dalbagni G, Bochner B, Herr H, Donat SM. Does body mass index affect survival of patients undergoing radical or partial cystectomy for bladder cancer? J Urol 2005;173:1513-7.

17. Kok VC, Zhang HW, Lin CT, Huang SC, Wu MF. Positive association between hypertension and urinary bladder can- cer: epidemiologic evidence involving 79,236 propensity score-matched individuals. Ups J Med Sci 2018;123:10915.

18. Liu JY, Li YH, Liu ZW, Zhang ZL, Ye YL, Yao K, et al. Influence of body mass index on oncological outcomes in patients with upper urinary tract urothelial carcinoma treated with radical nephroureterectomy. Int J Urol 2014; 21:136-42.

19. Wang Q, Zhang T, Wu J, Wen J, Tao D, Wan T, et al. Prognosis and risk factors of patients with upper urinary tract urothelial carcinoma and postoperative recurrence of bladder cancer in central China. BMC Urol 2019;19:24.

20. Greene FL, Page DL, Fleming ID, Fritz AG, Balch CM, Haller DG, et al., editors. AJCC cancer staging manual. 6th ed. New York: Springer-Verlag; 2002.

21. Inamoto $T$, Komura $K$, Watsuji $T$, Azuma H. Specific body mass index cut-off value in relation to survival of patients with upper urinary tract urothelial carcinomas. Int J Clin Oncol 2012;17:256-62.

22. Calle EE, Kaaks R. Overweight, obesity and cancer: epidemiological evidence and proposed mechanisms. Nat Rev Cancer 2004;4:579-91.

23. Chen JS, Lu CL, Huang LC, Shen CH, Chen SC. Chronic kidney disease is associated with upper tract urothelial carcinoma: a nationwide population-based cohort study in Taiwan. Medicine (Baltimore) 2016;95:e3255.

24. Barrett-Connor E, Khaw KT. Is hypertension more benign when associated with obesity? Circulation 1985;72:53-60. 